\title{
Conformational changes and molecular motion of poly(ethylene terephthalate) annealed above glass transition temperature
}

\author{
J.-M. Huang ${ }^{\text {a,b }}$, P.P. Chu ${ }^{\text {c }}$ F.-C. Chang ${ }^{\text {b,* }}$ \\ ${ }^{a}$ Department of Chemical Engineering, Van Nung Institute of Technology, Chung-Li, Taiwan \\ ${ }^{\mathrm{b}}$ Institute of Applied Chemistry, National Chiao Tung University, Hsinchu, Taiwan \\ ${ }^{\mathrm{c}}$ Department of Chemistry, National Central University, Chung-Li, Taiwan
}

Received 29 January 1998; received in revised form 19 March 1999; accepted 6 May 1999

\begin{abstract}
Conformational conversion and molecular dynamics of the amorphous poly(ethylene terephthalate) (PET) annealed above $T_{\mathrm{g}}$ were investigated by ${ }^{13} \mathrm{C}$ high-resolution solid-state NMR and differential scanning calorimetry (DSC). Rapid increase in the PET trans content and crystallinity were observed near the onset crystallization temperature $\left(\cong 120^{\circ} \mathrm{C}\right)$. By comparing both changes in conformation and crystallinity during thermal annealing, we found that the trans conformer increases continuously while the degree of crystallinity levels off during the later stage of annealing. The ${ }^{1} \mathrm{H}$ spin-lattice relaxation time in the rotating frame $\left(T_{1 \rho}^{\mathrm{H}}\right)$ correlates linearly with PET crystallinity but less well with the trans content. A three-domain model containing crystalline (all trans), constrained noncrystalline (trans rich) and amorphous (gauche rich) phases satisfactorily explains the relationship among the PET conformation, crystallinity and annealing conditions. This study complements the prior study of molecular motion by $T_{1 \rho}^{\mathrm{C}}$ and illustrates the importance of the trans conformer to induce PET crystallization. (C) 1999 Elsevier Science Ltd. All rights reserved.
\end{abstract}

Keywords: Poly(ethylene terephthalate); Solid-state NMR; Crystallinity

\section{Introduction}

Structure and property changes in poly(ethylene terephthalate) (PET) caused by annealing have been widely studied. Neighboring aryl group in PET exhibits both gauche and trans conformers. It is widely observed [1-6] that the conformation is a function of both temperature and annealing time which affect both the molecular dynamics as well as the crystallinity. Le Bourvellec et al. [1] reported that the kinetic of PET crystallization is controlled by the initial orientation and the annealing temperature. Galli et al. [2] revealed by means of infrared spectroscopy and differential scanning calorimetry that PET chain segments of trans conformer begin to crystallize even below its $T_{\mathrm{g}}$. Koenig et al. [3] reported that the relative conformer composition for PET crystallized from dilute dimethyl phthalate solution is a function of temperature. They also reported that the amorphous PET film has a trans content of 14\%. Havens and Van der Hart et al. [4] showed by multiple pulse dipolar decoupling techniques that three domains;

\footnotetext{
*Corresponding author. Tel.: +886-3-5712121-56502; fax: +886-35723764.

E-mail address: changfc@ @cc.nctu.edu.tw (F.-C. Chang)
}

crystalline, constraint non-crystalline and amorphous domains with distinct difference in mobility are observed. However, the structure of the intermediate non-crystalline region is not clear. Schaefer et al. [7] showed that annealing below $T_{\mathrm{g}}$ reduces the mid-kilohertz rotational segmental motions of the methylene groups in PET deduced from carbon-13 rotating-frame relaxation time $T_{1 \rho}^{\mathrm{C}}$. In general, the trans conformer is the major component in the crystallization phase while the gauche conformer is present primarily in the chain folds and the amorphous phase as the chain ends or ties molecules. Crystallinity of a polymer is a sensitive function of both crystallization temperature and annealing time. In a recent study [8], it was found that the conformation in the crystalline PET is totally trans, but only $14 \%( \pm 5 \%)$ trans appears in the amorphous PET. Additionally, the average gauche torsion angle of $70^{\circ}$ $\left( \pm 9^{\circ}\right)$ was identified [8]. Despite a large number of investigations, the relationship among PET conformation, crystallinity and molecular motions is not completely understood. Present paper will focus on the change of PET transgauche ratio, the motions in different domains and the crystallization growth as a function of annealing temperature and time.

High-resolution solid-state NMR is an effective tool to 


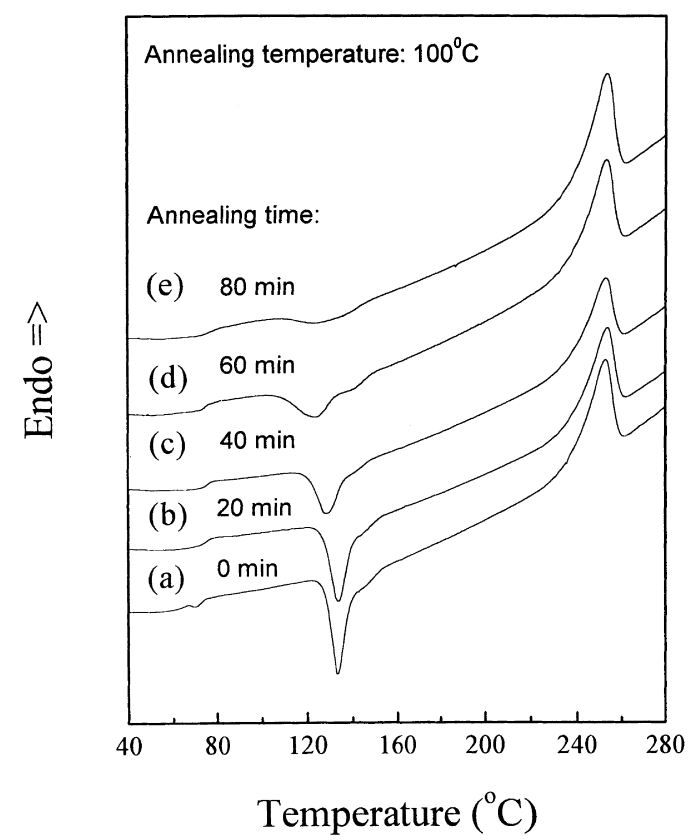

Fig. 1. DSC scans of PET samples annealed at $100^{\circ} \mathrm{C}$ for various times: (a) 0 (quenched PET); (b) 20; (c) 40; (d) 60; (e) $80 \mathrm{~min}$.

determine polymer chain conformation and to address issues related to polymer dynamics [9-17]. In this study, we combine ${ }^{13} \mathrm{C} \mathrm{CP/MAS} \mathrm{NMR} \mathrm{and} \mathrm{DSC} \mathrm{measurements} \mathrm{to}$ investigate the relationships among conformation, dynamics and crystallization behaviors in PET. Unlike previous ${ }^{1} \mathrm{H}$ or ${ }^{13} \mathrm{C}$ relaxation studies, we have used the $T_{1 \rho}^{\mathrm{H}}$ observed indirectly from ${ }^{13} \mathrm{C}$ to characterize the molecular dynamics. The obtained quantity represents the averaged ensemble of a domain within $50 \AA$ which is larger than that from $T_{1 \rho}^{\mathrm{C}}$ $(<10 \AA)^{7}$. This appears to be a suitable choice for study the dynamics in different PET domains.

\section{Experimental}

\subsection{Sample preparation}

The PET used in this study is a commercial product with I.V. $=1.0$ obtained from the Shinkong Synthetic Fibers Corporation of Taiwan. PET was dried in vacuum at $105^{\circ} \mathrm{C}$ for $48 \mathrm{~h}$ before melt processing to avoid possible degradation caused by moisture. The amorphous PET was prepared by melting the dried PET pellets in a Brabender and quenched immediately in liquid nitrogen. Then, these amorphous PET samples were annealed in a vacuum oven at $100^{\circ} \mathrm{C}$ for various time intervals (from $20 \mathrm{~min}$ to $24 \mathrm{~h}$ ). Samples were also annealed at different temperatures at a fixed time of $60 \mathrm{~min}$.

\subsection{Differential scanning calorimetry experiments}

DSC measurements were carried out in a Perkin-Elmer DSC-7 calorimetry. Samples were heated from 30 to $300^{\circ} \mathrm{C}$ with a heating rate of $10^{\circ} \mathrm{C} / \mathrm{min}$ under a nitrogen atmosphere.

\subsection{High-resolution solid-state NMR studies}

High-resolution solid-state ${ }^{13} \mathrm{C}$ NMR experiments were carried out on a Bruker DSX-300 spectrometer operating at resonance frequencies of 300.13 and $75.475 \mathrm{MHz}$ for ${ }^{1} \mathrm{H}$ and ${ }^{13} \mathrm{C}$, respectively. ${ }^{13} \mathrm{C} \mathrm{CP} / \mathrm{MAS}$ NMR spectra were measured by the following conditions: $90^{\circ}$ pulse width, $3.9 \mu \mathrm{s}$; pulse delay time, $3 \mathrm{~s}$; acquisition time, $30 \mathrm{~ms}$. All NMR spectra were recorded with broad band proton decoupling $\left(\nu_{1}=64 \mathrm{kHz}\right)$, and a conventional cross-polarization pulse sequence. The magic-angle sample spinning (MAS) rate of $4 \mathrm{kHz}$ was used to avoid overlapping resonance lines. Proton spin-lattice relaxation times in the rotating frame $\left(T_{1 \rho}^{\mathrm{H}}\right)$ were measured indirectly via carbon observation with a spin lock pulse prior to cross-polarization. Data acquisitions were performed with ${ }^{1} \mathrm{H}$ decoupling $\left(\nu_{1}=64 \mathrm{kHz}\right)$, using spin-lock times ranging from 0.2 to $12 \mathrm{~ms}$. The contact time was $1.5 \mathrm{~ms}$.

\section{Results and discussion}

\subsection{Differential scanning calorimetry analyses}

DSC heating scanning thermographs of the PET after annealing at $100^{\circ} \mathrm{C}$ for various time are shown in Fig. 1, and the results are summarized in Table 1. It is evident that there is a distinct glass transition temperature $\left(T_{\mathrm{g}}\right)$, an exothermic recrystallization peak $\left(T_{\mathrm{c}}\right)$, and an endothermic

Table 1

DSC data of PET annealing at $100^{\circ} \mathrm{C}$ for various times

\begin{tabular}{|c|c|c|c|c|c|c|c|c|c|c|c|}
\hline \multirow[t]{2}{*}{ Annealing time $(\mathrm{min})$} & \multicolumn{5}{|c|}{ Crystallization } & \multicolumn{4}{|l|}{ Melting } & \multirow{2}{*}{$\begin{array}{l}\text { Difference } \\
\Delta H_{\mathrm{f}}-\Delta H_{\mathrm{c}}(\mathrm{J} / \mathrm{g})\end{array}$} & \multirow{2}{*}{$\begin{array}{l}\text { Crystallinity } \\
W_{\mathrm{c}}(\%)\end{array}$} \\
\hline & $T_{\mathrm{g}}\left({ }^{\circ} \mathrm{C}\right)$ & Onset $\left({ }^{\circ} \mathrm{C}\right)$ & $T_{\mathrm{c}}\left({ }^{\circ} \mathrm{C}\right)$ & $\Delta T_{\mathrm{c}}\left({ }^{\circ} \mathrm{C}\right)$ & $\Delta H_{\mathrm{c}}(\mathrm{J} / \mathrm{g})$ & Onset $\left({ }^{\circ} \mathrm{C}\right)$ & $T_{\mathrm{m}}\left({ }^{\circ} \mathrm{C}\right)$ & $\Delta T_{\mathrm{m}}\left({ }^{\circ} \mathrm{C}\right)$ & $\Delta H_{\mathrm{f}}(\mathrm{J} / \mathrm{g})$ & & \\
\hline $0^{\mathrm{a}}$ & 73.6 & 122.7 & 133.2 & 40.6 & 31.01 & 225.2 & 252.3 & 37.5 & 36.04 & 5.03 & 4.2 \\
\hline 20 & 74.4 & 119.1 & 128.9 & 40.8 & 28.68 & 225.7 & 253.1 & 38.4 & 35.66 & 6.98 & 5.8 \\
\hline 40 & 75.6 & 115.0 & 128.5 & 45.2 & 26.14 & 226.8 & 252.3 & 35.9 & 35.23 & 9.09 & 7.6 \\
\hline 60 & 75.7 & 106.9 & 128.1 & 54.4 & 21.94 & 226.9 & 252.8 & 36.3 & 36.84 & 14.90 & 12.4 \\
\hline 80 & 76.5 & 105.5 & 128.6 & 56.1 & 12.96 & 223.9 & 253.0 & 40.4 & 38.75 & 25.79 & 21.5 \\
\hline
\end{tabular}

${ }^{\text {a }}$ Annealing time $0 \mathrm{~min}$ is the quenched PET. 

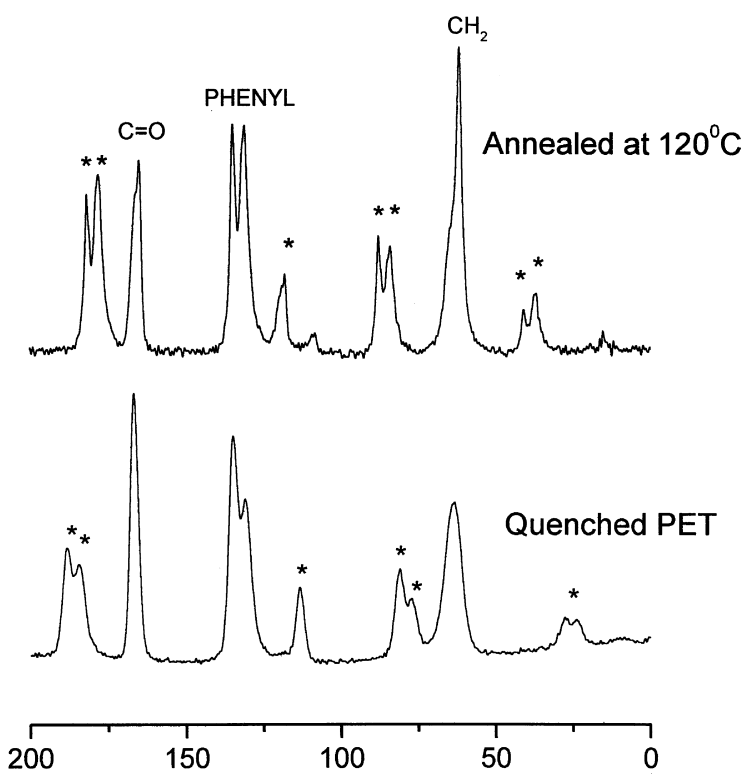

\section{Chemical shift (ppm)}

Fig. 2. ${ }^{13} \mathrm{C}$ CP/MAS NMR spectra of PET: (a) quenched; (b) annealed at $120^{\circ} \mathrm{C}$ for $60 \mathrm{~min}$. Asterisks denote spinning sidebands.
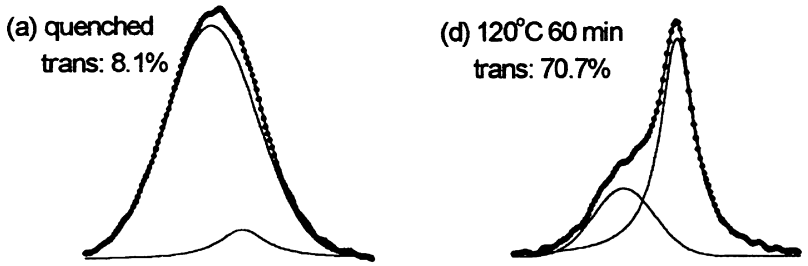

(b) $100^{\circ} \mathrm{C} 60 \mathrm{~min}$

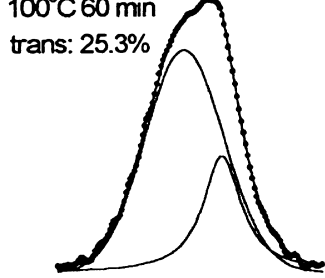

(e) $160^{\circ} \mathrm{C} 60 \mathrm{~min}$

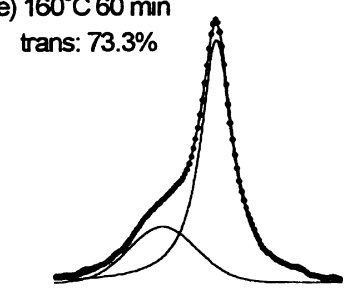

(c) $100^{\circ} \mathrm{C} 24 \mathrm{hr}$ trans: $51.9 \%$

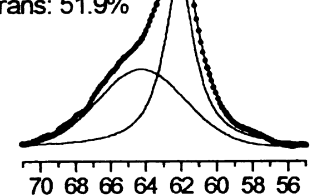

Chemical shift (ppm)

melting peak $\left(T_{\mathrm{m}}\right)$ in all of these heating scans. The exothermic peak corresponds to the crystallization of amorphous regions. The observed glass transition temperature increases slightly with annealing time. In addition, the onset temperature of the recrystallization is reduced with annealing time, and the quenched (amorphous) PET has the highest recrystallization temperature. This earlier recrystallization phenomenon of the annealed PET can be interpreted as the result of a nucleation effect for the partially crystallized PET after annealing. Annealing above glass transition temperature $\left(T_{\mathrm{g}}\right)$ induces the segmental mobility of PET, and reduces the free energy barrier for nuclei formation which is able to accelerate the rate of recrystallization. The recrystallization peak widths $\left(\Delta T_{\mathrm{c}}\right)$ for the annealed PET samples are broader than that of the quenched PET, and increase with increasing annealing time. As would be expected, the quenched PET has the largest heat of recrystallization $\left(\Delta H_{\mathrm{c}}\right)$, and decreases with increasing annealing time. The degree of crystallinity of PET, $\left(W_{\mathrm{c}}\right)$, is determined [18] as follow:

$W_{\mathrm{c}}=\Delta H_{\mathrm{m}, \mathrm{obs}} / \Delta H_{\mathrm{m} 0}$

where $\Delta H_{\mathrm{m}, \mathrm{obs}}=\Delta H_{\mathrm{f}}-\Delta H_{\mathrm{c}}, \Delta H_{\mathrm{f}}$ is the heat of melting and $\Delta H_{\mathrm{c}}$ is the heat of recrystallization. The absolute value of the heat of fusion of the fully crystalline PET is $\Delta H_{\mathrm{m} 0}=120 \mathrm{~J} / \mathrm{g}$ (or $5.8 \mathrm{kcal} / \mathrm{mol}$ ) [18] The degree of crystallinity in PET is listed in the last column of Table 1.

\section{2. ${ }^{13} \mathrm{C} C P / M A S$ NMR spectra}

Fig. 2 depicts ${ }^{13} \mathrm{C}$ CP/MAS NMR spectra for PET quenched and annealed at $120^{\circ} \mathrm{C}$ for $60 \mathrm{~min}$. The combination of dipolar decoupling and magic-angle spinning (MAS) results in sufficiently high resolution to resolve the methylene-, phenyl- and carbonyl-carbon lines at 63.7, 134.8 and $166.7 \mathrm{ppm}$, respectively. Sample preparation and thermal history have pronounced effects on the observed chemical shifts and the line shapes. The carbonyl resonance for the quenched PET $\left(\delta_{0}=166.7 \mathrm{ppm}\right)$ becomes narrower and an additional peak appears at $164.8 \mathrm{ppm}$ after annealing at $120^{\circ} \mathrm{C}$. Similarly, the methylene carbon $(63.7 \mathrm{ppm})$ for the quenched PET also shows an upfield peak (62 ppm) after annealing. This resonance can be reasonably decomposed into a Gaussian and a Lorentzian components separated by about $2 \mathrm{ppm}$. The decomposition provides direct quantification for conformations with annealing that will be discussed afterward.

\subsection{Annealing effect on conformational change}

In general, the methylene carbon resonance of the PET comprises of an up-field narrower component and a broader down-field component. Previous ${ }^{13} \mathrm{C}$ NMR works [7,19] have assigned the former as the methylene carbons in the trans conformer, and the latter in the gauche conformer. The chemical shift difference, the line widths, and the relative area ratios of these two components are resolved. The overall

Fig. 3. Methylene carbon resonance peaks for PET: (a) quenched; (b) annealed at $100^{\circ} \mathrm{C}$ for $60 \mathrm{~min}$; (c) annealed at $100^{\circ} \mathrm{C}$ for $24 \mathrm{~h}$; (d) annealed at $120^{\circ} \mathrm{C}$ for $60 \mathrm{~min}$; (e) annealed at $160^{\circ} \mathrm{C}$ for $60 \mathrm{~min}$; and (f) annealed at $200^{\circ} \mathrm{C}$ for $60 \mathrm{~min}$. Dots are experimental data, and the solid line is a fit based on the combination of Gaussian and Lorentzian functions. 
Table 2

Conformational changes of methylene carbons of PET at various annealing conditions

\begin{tabular}{|c|c|c|c|}
\hline Annealing temperature $\left({ }^{\circ} \mathrm{C}\right)$ & Annealing time (min) & Trans $(\%)$ & Gauche (\%) \\
\hline Quenched PET & 0 & 8.1 & 91.9 \\
\hline 100 & 20 & 18.4 & 81.6 \\
\hline 100 & 40 & 21.6 & 78.4 \\
\hline 100 & 60 & 25.3 & 74.7 \\
\hline 100 & 80 & 30.2 & 69.8 \\
\hline 100 & 1440 & 51.9 & 48.1 \\
\hline 120 & 20 & 69.1 & 30.9 \\
\hline 120 & 40 & 69.5 & 31.5 \\
\hline 120 & 60 & 70.7 & 29.3 \\
\hline 120 & 80 & 71.4 & 28.6 \\
\hline 120 & 1440 & 78.8 & 21.2 \\
\hline 120 & 60 & 70.7 & 29.3 \\
\hline 140 & 60 & 71.9 & 28.1 \\
\hline 160 & 60 & 73.3 & 26.7 \\
\hline 180 & 60 & 79.5 & 20.5 \\
\hline 200 & 60 & 84.8 & 15.2 \\
\hline
\end{tabular}

resonance peak is fitted well to the sum of a Lorentzian function for the upfield narrow component and a Gaussian for the down field broad component. As an example, the experimental line shape and the decomposition results are displayed in Fig. 3: (a) the quenched PET; (b) annealed at $100^{\circ} \mathrm{C}$ for $60 \mathrm{~min}$; and (c) annealed at $100^{\circ} \mathrm{C}$ for $24 \mathrm{~h}$. The quenched PET possesses $8.1 \%$ trans conformer which is in agreement with the range predicted by previous works $[3,20,21]$. It is worth noting that the trans conformer can exist in both crystalline and amorphous phases while the gauche conformer appears mostly in the amorphous region. It is clear that the amount of the trans conformer increases

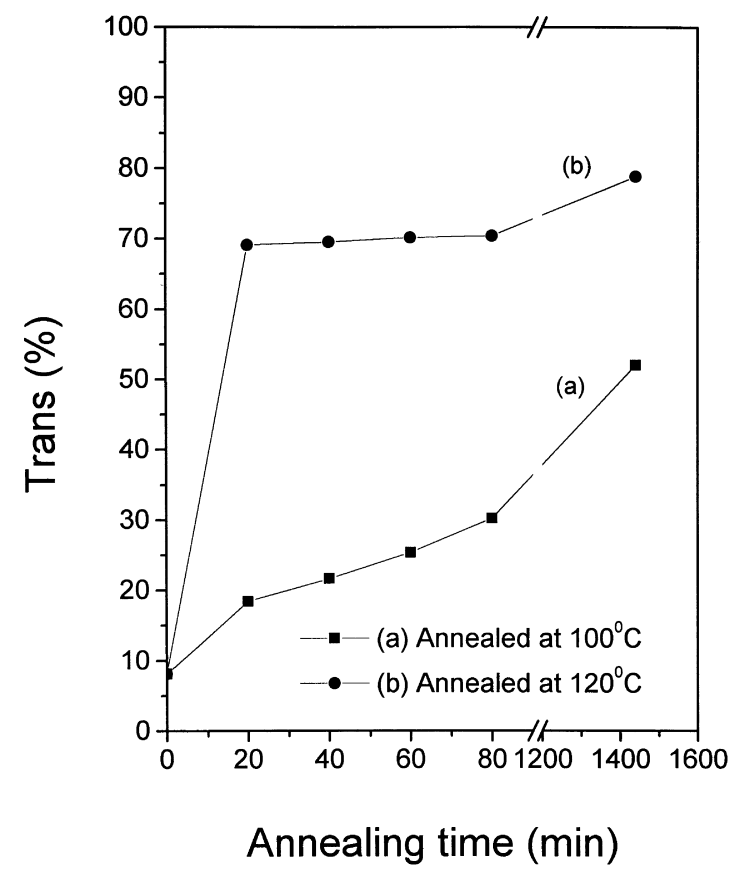

Fig. 4. Trans content as a function of annealing time for PET annealed at indicated temperatures: (a) $100^{\circ} \mathrm{C}(\boldsymbol{\square}) ;$ (b) $120^{\circ} \mathrm{C}(\bullet)$. significantly from 8.1 to $51.9 \%$, and the line width for the trans resonances become slightly narrower after annealing for $24 \mathrm{~h}$. This gives a direct measurement of the conformational change of the methylene carbons from gauche form to trans form upon annealing above its $T_{\mathrm{g}}$. Annealing below its $T_{\mathrm{g}}$ does not provide sufficient energy to convert into the thermodynamically more stable trans conformer [22]. The increase in trans fraction follows the same trend as the increase of PET crystallinity. Conformation conversion is also observed with changing annealing temperature as shown in Fig. 3: (d) $120^{\circ} \mathrm{C}$, (e) $160^{\circ} \mathrm{C}$, and (f) $200^{\circ} \mathrm{C}$, after annealing for $60 \mathrm{~min}$. The conformation is still mostly in

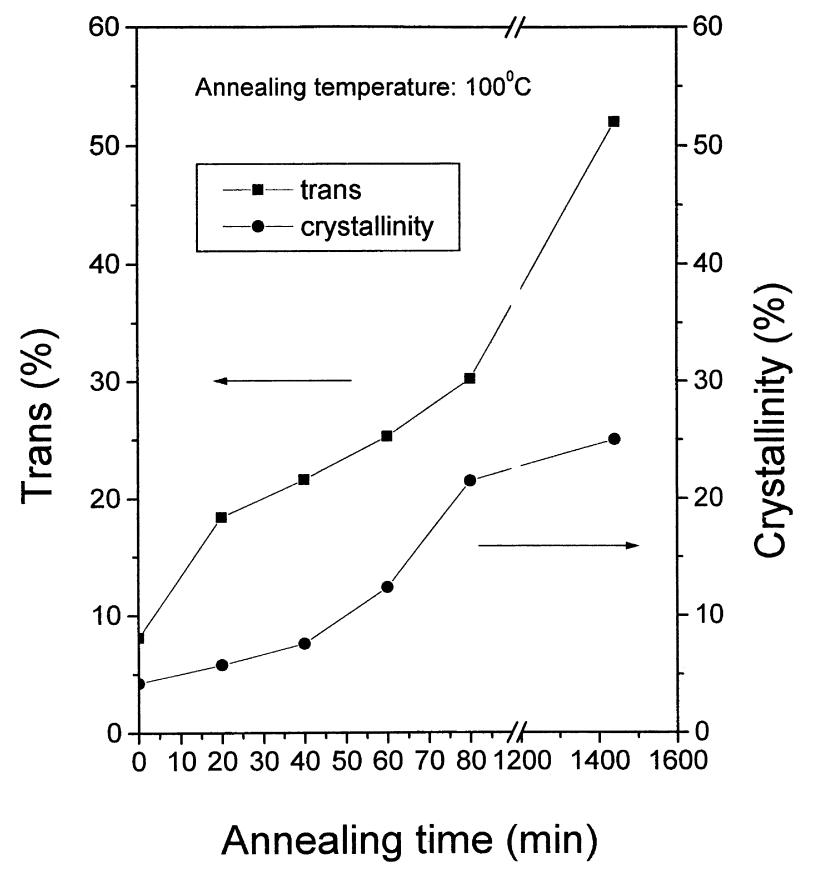

Fig. 5. Trans content and crystallinity of PET as a function of annealing time. 


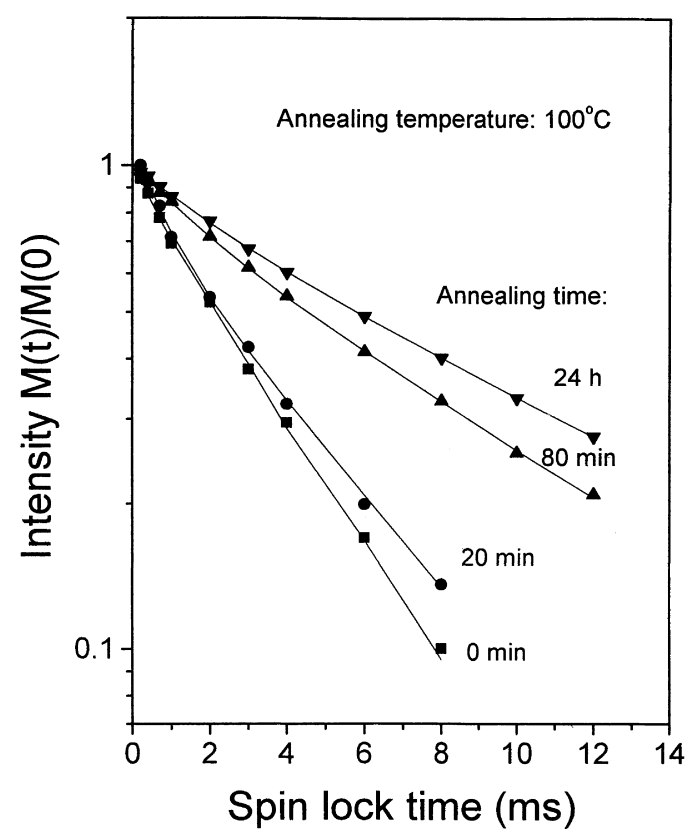

Fig. 6. Semi-logarithmic plots of the magnetization intensity of $62 \mathrm{ppm}$ (methylene) as a function of spin-lock time for PET annealed at $100^{\circ} \mathrm{C}$ for the time indicated. Annealing time 0 min corresponds to the quenched PET.

gauche form, when annealed at $100^{\circ} \mathrm{C}$ for the same annealing time. Raising annealing temperature to above $120^{\circ} \mathrm{C}$ causes rapid increase the fraction of the trans conformer, as shown in Fig. 3(d)-(f). The trans fraction increases from $25.3 \%$ at $100^{\circ} \mathrm{C}$ to $70.7 \%$ at $120^{\circ} \mathrm{C}, 73.3 \%$ at $160^{\circ} \mathrm{C}$ and $84.8 \%$ at $200^{\circ} \mathrm{C}$. It is more than just a mere coincidence that the observed rapid conversion from gauche form to trans form occurs at a temperature $\left(120^{\circ} \mathrm{C}\right)$ identical to the temperature of the PET onset crystallization. This observation indicates that a close relationship between the fraction of the trans conformation and the crystallinity.

The conformer distributions after various annealing conditions are tabulated in Table 2 for comparison. Both annealing time and temperature affect the conformer distribution, but their effects are more pronounced at higher annealing temperatures, especially above $120^{\circ} \mathrm{C}$. Fig. 4 shows plots of trans content in PET versus annealing time for annealing at 100 and $120^{\circ} \mathrm{C}$, respectively. Fig. 4(a) reveals a gradual increase in the trans fraction by annealing at $100^{\circ} \mathrm{C}$. When annealed at $120^{\circ} \mathrm{C}$, the trans fraction quickly jumps to $69 \%$ within $20 \mathrm{~min}$ and gradually increases up to $79 \%$ after $24 \mathrm{~h}$ as shown in Fig. 4(b). The increase in the trans fraction is in accordance with the increase in PET crystallinity determined by DSC. Fig. 5 compares the trans fraction and crystallinity versus annealing time at $100^{\circ} \mathrm{C}$. It is interesting to note that both trans content and crystallinity increase with annealing time. However, the crystallinity levels off at ca. $23 \%$ but the trans conformer continues to increase with annealing time. This result suggests that conversion into the more stable trans conformation precedes the formation of the ordered crystallites. During the process of crystallite formation, fraction of the trans conformer is excluded from the PET crystalline phase, forming the interface between crystalline and amorphous domains. Conversion to the trans conformer can be considered as the precursor for the subsequent crystallization.

\subsection{Proton spin-lattice relaxation $\left(T_{1 \rho}^{\mathrm{H}}\right)$}

Conformational conversion to trans form induces the subsequent crystallization and results in slower molecular motion. Proton spin-lattice relaxation time in the rotating frame, $T_{1 \rho}^{\mathrm{H}}$, via resolved carbon resonance provides a means to characterize molecular motion in polymers. Molecular motions of carbonyl, aromatic and $\mathrm{CH}_{2}$ segment as a function of annealing conditions based on $T_{1 \rho}^{\mathrm{C}}$ have been investigated previously [7]. Current study uses the parameter of $T_{1 \rho}^{\mathrm{H}}$ with a clear focus on motion where the individual relaxation behaviors are averaged over a larger domain due to spin-diffusion. Although the mode of molecular motion detected is comparable by both methods, $T_{1 \rho}^{\mathrm{H}}$ takes the overall averages of a larger domain. The relaxation for an individual molecular segment in repeating unit is equal for the same reason. If the domain is large enough, distinct relaxations from different morphological domains appear. The magnetization decay curves of the ${ }^{13} \mathrm{C}$ signal for methylene carbons of the quenched and annealed PET at $100^{\circ} \mathrm{C}$ from $20 \mathrm{~min}$ to $24 \mathrm{~h}$ are plotted on a semi-logarithmic scale vs. proton spin-lock time as shown in Fig. 6. In this

Table 3

$T_{1 \rho}^{\mathrm{H}}$ values of $62 \mathrm{ppm}$ of PET at various annealing conditions

\begin{tabular}{|c|c|c|c|c|c|}
\hline \multirow[t]{2}{*}{ Annealing temperature $\left({ }^{\circ} \mathrm{C}\right)$} & \multirow[t]{2}{*}{ Annealing time (min) } & \multicolumn{2}{|l|}{ Two components fit } & \multicolumn{2}{|c|}{ Stretch exponential fit } \\
\hline & & Short time component (ms) & Long time component (ms) & $\alpha$ & $T_{1 \rho}^{\mathrm{H}}(\mathrm{ms})$ \\
\hline Quenched PET & 0 & 0.4 & 3.5 & 0.93 & 3.2 \\
\hline 100 & 20 & 0.5 & 4.1 & 0.90 & 3.6 \\
\hline 100 & 60 & 1.4 & 6.1 & 0.88 & 5.4 \\
\hline 100 & 80 & 2.1 & 8.9 & 0.85 & 6.8 \\
\hline 100 & 1440 & 2.7 & 11.1 & 0.75 & 8.7 \\
\hline 120 & 60 & 1.3 & 9.7 & 0.78 & 7.4 \\
\hline 160 & 60 & 1.1 & 10.5 & 0.70 & 9.1 \\
\hline 200 & 60 & 0.9 & 13.4 & 0.65 & 12.5 \\
\hline
\end{tabular}




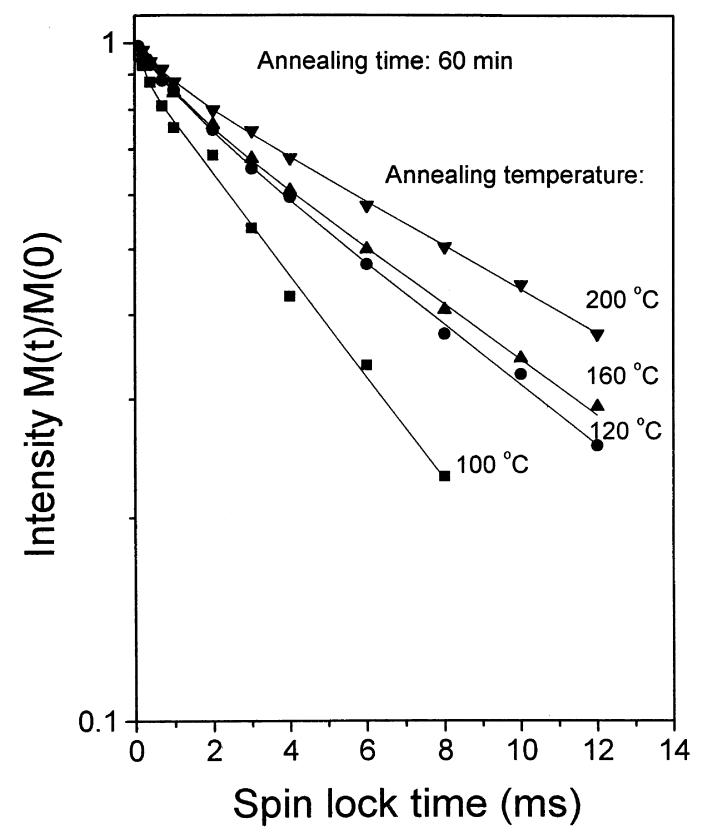

Fig. 7. Semi-logarithmic plots of the magnetization intensity of $62 \mathrm{ppm}$ (methylene) as a function of spin-lock time for PET annealed at different temperatures for $60 \mathrm{~min}$,

bi-exponential approach, these two components correspond to the relaxation of PET protons located in the more mobile (short time component) and the more rigid (long time component) regions. The $T_{1 \rho}^{\mathrm{H}}$ values obtained from the methylene carbon $(62 \mathrm{ppm})$ of PET are summarized in Table 3. The $T_{1 \rho}^{\mathrm{H}}$ for the long time component increases gradually from $3.5 \mathrm{~ms}$ for the quenched sample to $11.1 \mathrm{~ms}$ for the sample after annealing $1440 \mathrm{~min}$ at $100^{\circ} \mathrm{C}$. Changing

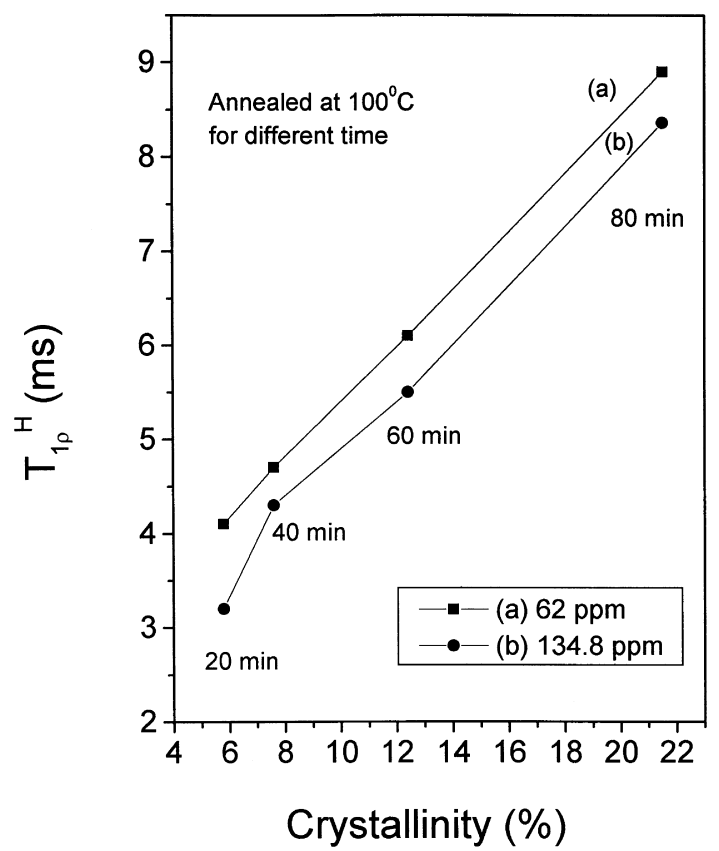

Fig. 8. $T_{1 \rho}^{\mathrm{H}}$ values as a function of PET crystallinity (a) 62 ; (b) $134.8 \mathrm{ppm}$ (methylene).

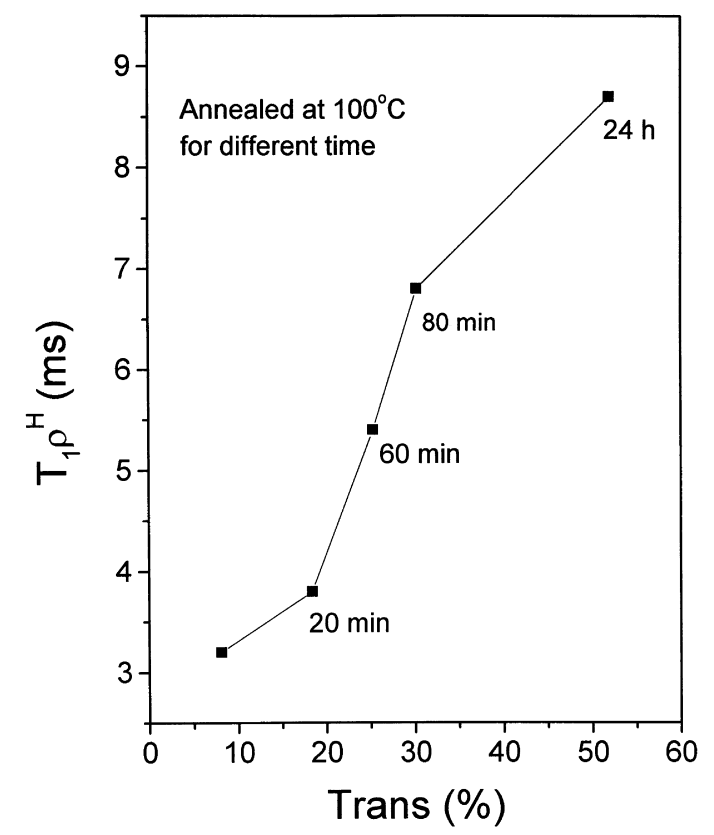

Fig. 9. Plot of $T_{1 \rho}^{\mathrm{H}}$ values as a function of trans content in PET.

the annealing temperature has similar effects on molecular dynamics. Fig. 7 shows the semi-logarithmic plots of the magnetization intensity of the methylene as a function of spin-lock time for PET annealed from 100 to $200^{\circ} \mathrm{C}$ for a fixed time of $60 \mathrm{~min}$. Increasing annealing temperature also results in longer $T_{1 \rho}^{\mathrm{H}}$. Proton relaxes slower when PET is annealed at a higher temperature. The distribution of relaxation time is expressed by the stretch exponential approximation. The stretch exponent $\alpha$ equals 1 for homogeneous relaxation, while $\alpha$ is reduced for more inhomogeneous distribution due to the hierarchical coupled relaxation behavior. The exponent $\alpha$ and the averaged relaxation time $T_{1 \rho}^{\mathrm{H}}$ $(\alpha)$ resulting from the stretch exponential analysis are summarized in the last two columns in Table 3. Gradual decrease of the exponent $\alpha$ is observed which implies that the relaxation time distribution becomes more severe as the molecular motion is reduced $\left(T_{1 \rho}^{\mathrm{H}}(\alpha)\right.$ increases $)$ with more severe annealing conditions.

Without specifying motion of the individual molecular moiety, the increase of $T_{1 \rho}^{\mathrm{H}}$ value can be used directly as the measure of the reduction of PET molecular mobility averaged over the diffusion length (estimated to within $50 \AA$ ). The correlation of the $T_{1 \rho}^{\mathrm{H}}$ with crystallinity is shown in Fig. 8. Interestingly, the increase of $T_{1 \rho}^{\mathrm{H}}$ with crystallinity follows a linear relationship rather well. However, the linear relationship between $T_{1 \rho}^{\mathrm{H}}$ and trans content (Fig. 9) is not as well as in Fig. 8. $T_{1 \rho}^{\mathrm{H}}$ is an average of spatial length limited by spin-diffusion. These observed results imply that the $T_{1 \rho}^{\mathrm{H}}$ of the long time component is a measure for the relatively rigid domain, which is only indirectly related to the trans content. In addition, the trans conformer is also present in the soft amorphous domain. Combining these results it is clear that the amorphous phase is made up of 
$(\operatorname{trans} 8 \%$ )
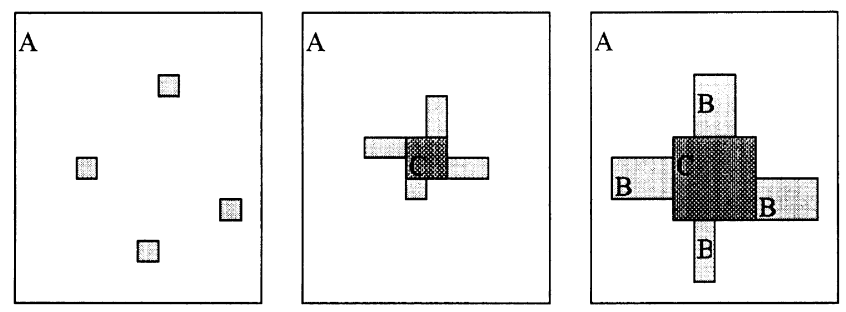

$(\operatorname{trans} 80 \%)$

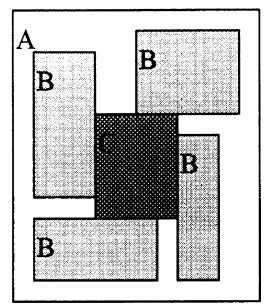

\section{A $\square$ : amorphous domains \\ $\mathrm{B} \square$ : constrained noncrystalline domains

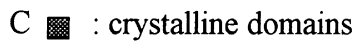

Fig. 10. Schematic diagrams show the relationship between conformation conversion and crystallinity growth in PET.

high content of gauche conformer while the constrained noncrystalline phase is made up of chains rich in trans conformer. The three-domain result is consistent with the previous $T_{1 \rho}^{\mathrm{H}}$ study using the multiple pulse sequence by Havens and Van der Hart [4]. The relationship between conformational conversion and crystallinity growth can be depicted in Fig. 10. These three domains correspond to crystalline (all trans), constrained noncrystalline (trans rich), and amorphous (gauche rich) phases. The quenched PET contains mostly the amorphous domain, only small amount of constrained noncrystalline is present. With increasing annealing temperature and time both the crystalline and the constrained noncrystalline domains grow simultaneously. However, noncrystalline domain continuously increases even after the size of the crystalline domain is leveled off.

\section{Conclusion}

In this study, both DSC and NMR measurements have been utilized to determine the crystallinity and conformational changes of PET. The up-field Lorentzian line shape in the methylene resonance $(\backsim 63 \mathrm{ppm})$ corresponds to the trans conformer which increases with increasing of annealing time and temperature, while the down field resonance (Gaussian) corresponds to the gauche conformer. The appearance of the larger fraction of the trans conformer after annealing also results in higher crystallinity and lower methylene line widths. For the first time, we have observed the phenomenon of continuous increase of the trans conformer beyond the point where the degree of crystallinity has leveled off. These additional trans conformers grow in the amorphous region and the vicinity of the interface. It appears that the gauche to trans conversion proceeds before the subsequent PET crystallization and the trans conformers can be considered as a precursor for the PET crystallization. ${ }^{1} \mathrm{H}$ spin-lattice relaxation time in the rotating frame $\left(T_{1 \rho}^{\mathrm{H}}\right)$ is found to correlate linearly with PET crystallinity, but less linear with trans content. It is clear that the trans conformer possesses different mobility in the amorphous and the ordered crystalline domains. A threedomain model containing crystalline (all trans), constrained noncrystalline (trans rich), and amorphous phase (gauche rich) satisfactorily explains the relationship among the PET conformation, crystallinity and annealing conditions.

\section{Acknowledgements}

Financial support for this research was provided by the National Science Council of the Republic of China under contract number NSC-87-2216-E-009-006, and NSC-872216-M-008-004. Fruitful discussion with Dr. Hew-Der $\mathrm{Wu}$ is greatly appreciated.

\section{References}

[1] Le Bourvellec G, Monnerie L, Jarry JP. Polymer 1987;28:1712.

[2] Galli R, Canetti M, Sadocco P, Seves A, Vicini L. J Polym Sci, Polym Phys Edn 1983;21:717.

[3] Lin SB, Koenig JL. J Polym Sci, Polym Phys Edn 1982;20:2277.

[4] Havens JR, Van der Hart DL. Macromolecules 1985;18:1663.

[5] Goschel U. Polymer 1996;37:4049.

[6] Fakirov S, Fischer EW, Hoffmann R, Schmidt G. Polymer 1977; 18:1121.

[7] Sefcik MD, Schaefer J, Stejskal EO, Mckay RA. Macromolecules 1980;13:1132.

[8] Schmidt-Rohr K, Hu W, Zumbulyadis N. Science 1998;280:714.

[9] Gao Z, Molnar A, Morin FG, Eisenberg A. Macromolecules 1992;25:6460.

[10] McBrierty VT, Douglass DC, Kwei TK. J Magn Reson Chem 1994;32:853.

[11] Campbell GC, Van der Hart DL. J Magn Reson 1992;96:69.

[12] NMR spectroscopy of polymers. In: Ibbett RN, editor. London: Blackie Academic and Professional, 1993.

[13] Solid state NMR of polymers. In: Mathias LJ, editor. New York: Plenum Press, 1988.

[14] Komoroski RA. High resolution NMR spectroscopy of synthetic polymers in bulk. In: Marchjand, editor. Methods in stereochemical analysis, 7. Deerfield Beach, FL: VCH, 1986. 
[15] Schmidt-Rohr K, Spiess HW. Multidimensional solid-state NMR and polymers, London: Academic Press, 1994.

[16] Dabbagh G, Weiky DP, Tycko R. Macromolecules 1994;27:6183.

[17] KitamaruR, Horii F, Murayama K. Macromolecules 1986;19:636.

[18] Roberts RC. Polymer 1969;10:113.
[19] Tang P, Reimer JA, Denn MM. Macromolecules 1993;26:4269.

[20] Ajji A, Guevremont J, Cole KC, Dumoulin MM. Polymer 1996;37:3707.

[21] Liu J, Koenig JL. Anal Chem 1987;59:2609.

[22] Illers KH, Breuer HJ. Colloid Sci 1963;18:1. 